\title{
Role of Anxiety in Radicalizing Political Attitudes: Experimental Evidence from Slovakia
}

\author{
Pavol Baboš, Aneta Világi \\ Department of Political Science, Faculty of \\ Arts, Comenius University, Bratislava, \\ Slovak Republic
}

\author{
Petra Soláriková \\ Department of Psychology, Faculty of Arts, \\ Comenius University, Bratislava, \\ Slovak Republic
}

\begin{abstract}
Proliferation of populist policies and strengthening of political populism in several liberal democracies has been accompanied by campaigns full of public anger, anxiety and fear. Our research contributes to understanding how negative emotions shape selected political attitudes. We designed an experiment with 72 participants randomly assigned to three groups. The aim was to impose anxiety by using a stimulus that is incidental, i.e. having unrelated content to the attitudes under study. In addition to self-reported emotional state measured by post-test survey, we also measured the heart rate activity. Regarding political attitudes, next to attitudes towards immigrants we measured attitudes towards marijuana decriminalization as well. Findings indicate that while imposed anxiety leads to more negative attitudes towards immigrants, there seems to be no such effect on attitudes towards marijuana. We explain the difference by presence/absence of the in-group/out-group division in the types of political attitudes under study.
\end{abstract}

Key words: anxiety, immigration, attitude change, attitude formation

\section{Introduction}

Political development in recent years has brought about an unprecedented intensity in political campaigns: intensive abuse of negative emotions in combination with misleading,

\section{Acknowledgement}

We would like to thank two anonymous reviewers for their constructive and inspiring reviews. This work was supported by Slovak Research and Development Agency under the contract No. APVV-170464 (Improving Communication on Democracy and EU Deficits), and also Scientific grant agency of the Ministry of Education - VEGA 1/0739/17.

Correspondence concerning this article should be addressed to Pavol Baboš, Department of Political Science, Faculty of Arts, Comenius University, Bratislava, Slovak Republic. E-mail: pavol.babos@uniba.sk

Received August 22, 2018 often false information. Admittedly, these tactics have been present in politics throughout the World (particularly blaming minorities for the country's misfortune, as in former Yugoslavia, Germany, and many more in the history). On the other hand, the level of prevalence and intensity of emotionally spun political campaign has recently increased (Trump's campaign in 2016, Leave campaign in Brexit referendum 2016, French elections 2017, Matteo Salvini in Italian election 2018, various parliamentary election in the post-communist part of the EU, and others). Populist-driven politics is also present in the region of Central and Eastern Europe, leaving Hungary and Poland accused of an illiberal turn and Czech and Slovak Republics facing massive increase of politicians, who claim not to be politicians (for example the 2016 billboard campaign of Boris Kollár; see Baboš, Világi \& Oravcová, 2016, p. 58) or, to be non-politicians (Babiš, 2013). Regardless of ideological (left- 
right) rooting of such populist leaders, their common mobilizing appeal lies in an antagonistic (in-group/out-group) wedge, treating "the people" as morally pure in-group and more or less specific "dishonest" out-group(s) (usually minorities) as a threat. As Mudde and Kaltwasser (2012) emphasized, populism is in essence based on moral politics. The implication is that the role of populist leaders is to construct in-group/out-group distinction using anxiety, fear and anger as main mobilizing tools for the campaign. On the other hand, positive emotions as pride, justice and purity help to construct in-group identity assumingly typical of "the people". Therefore, emotions have gained their significance not only in political campaigning but also in social sciences studying and explaining social reality. What connects modern populists in Western and Eastern Europe (and USA) is the issue of immigration they use to polarize societies. Whether it is labor migration as part of the EU's single market or illegal immigration highlighted by the 2015 refugee crisis, negative emotional campaigns attacking immigrants became one of the dominant parts of populists' electoral campaigns. Therefore, this study examines the influence of emotions on political attitudes, with particular focus on immigration attitudes. Specifically, we were interested in the role played by anxiety. We define anxiety as undirected aversive arousal, which is distinguished from similar emotions (such as anger or fear) by lacking a clear object (Ohman, 2000; Renshon et al., 2015).

In addition to the immigration issues, we tested also the relationship between anxiety and attitudes in another political issue that has been debated in western democracies - legalization of marijuana. We chose the marijuana issue because it does not have the element of in-group/ out-group division and thus is not a subset of issues easily abused by modern populists, who need the in-group/out-group division for their mobilization strategies.
Our findings contribute to the debate on the explanations provided by the affective intelligence theory (Marcus, Neumann, \& MacKuen, 2000). We argue that the role of emotions is not only an indirect one, blocking uncomfortable information out of the system, but their role is rather inhibiting the extremist attitudes. However, we find the effect to be dependent on issue characteristic. While anxiety played a significant role inhibiting extreme positions on the topic with an in-group/ out-group division (immigration), the effect was less visible in a topic without the clear in-group/out-group representation (marijuana legalization).

Our contribution to the literature on emotions and politics is twofold. First, we provide experimental evidence for the influence of emotions in political attitudes formation, even with a stimulus irrelevant to politics (Small \& Lerner, 2008; Renshon, Lee, \& Tingley, 2015). We use an experimental manipulation that is completely incidental to the political attitudes we measure. Even Renshon et al. (2015), despite using the same video to trigger anxiety, administered a text stimulus related to immigration issues.

Second, our study provides evidence for emotional influence on immigrant attitudes in a context different from the US. Particularly, the low level of experience with immigrants makes Slovakia rather different from the United States or other multicultural societies. The main argument here is that context plays an important role in attitudes formation, as the higher share of immigrants in society may significantly increase the intensity of direct inter-ethnic contacts.

\section{Theoretical Background}

\section{Attitudes towards Immigrants}

Attitudes towards immigrants and immigration have been the subject of social science research for several decades, although predomi- 
nantly in the American context. Hainmueller and Hopkins thus considered this area of study "ripe for comparative research" (2014, p. 234). Therefore, our study uses culturally different context to focus on attitudes towards immigrants. Slovakia, unlike the United States, is a typical emigrant rather than immigrant society. Limited (if any) experiences with immigrant minorities provide significantly different background for studying attitudes towards immigrants.

Although economy-based explanations dominated for a long time, recently the focus of political scientists includes psychological factors into the explanatory frames of immigration attitudes. Hainmueller and Hopkins (2014) provide a review of various approaches to studying and explaining attitudes towards immigrants and immigration policies. They highlight that the strand of research linking emotions to immigration attitudes is relatively new, with the first empirical study bringing anxiety into the picture being Brader, Valentino and Suhay (2008). Xenophobic tendencies of Slovak society has been explained from socio-economic perspective for long time (Haerpfer \& Wallace, 1998), however the psychological explanatory frames of immigration attitudes are less explored.

\section{Effects of Anxiety on Political Behavior}

Anxiety has caught the attention of political scientists because of its relatively well proved effects on voting behavior (e.g., Huddy et al., 2005; Ladd \& Lenz, 2008) and because the manipulation of this emotion in modern political campaigning is so prominent (Jerit, 2004; Brader, 2005). Anxiety as an emotion characterized by feelings of tension, uncertainty and lack of control is less targeted than for example fear or anger. The source of anxiety has not been precisely stated and thus, the usability of anxiety in political discourse is broader than that of fear, for instance. This is also a reason why immigra- tion-related anxiety might be present even in a country with limited (if any) experience with massive immigration like Slovakia.

Brader et al. (2008) claim to be not only the first to experimentally test the role of anxiety, but also the first to combine anxiety and perception of threat or harm as an alternative causal explanation. Change of belief or perception of consequences was a dominant explanatory route in the previous literature on immigration attitudes. The assumption was that a stimulus, e.g. newspaper article, affects the way people view immigration in regard to the size of the threat it constitutes or consequences it may bring about (Gilens, 1999; Mendelberg, 2001; Nelson \& Kinder, 1996; Valentino, Hutchings, \& White, 2002; Eagly \& Chaiken, 1993). Brader et al. (2008) depart from the Affective Intelligence Theory (AIT; Marcus, Neuman, \& MacKuen, 2000) and argue that people in an increased state of anxiety are not only more open to new information, but also more vulnerable to the information that is available, which may often be skewed, untrue or manipulated. Therefore, increased anxiety might lead to more negative attitudes towards immigration. Brader et al. (2008) conducted two experiments and proved that it is the anxiety, and not the perceived threat that mediates the relationship between group cues in immigration discourse and attitudes towards immigration.

\section{Affective Intelligence Theory}

Ladd and Lenz (2008) offered a reassessment of the Affective Intelligence Theory. The authors acknowledge the role anxiety plays in the political choices people make, especially vote choices. However, they question whether the decision-making model of AIT explains the anxiety's role better than its alternative: the Affect Transfer (AT) and Endogenous Affect (EA) hypotheses. The difference is that while AIT acknowledges only indirect role of anxiety, 
mainly in decreasing the heuristic importance in information processing, the latter two suggest a direct link between anxiety and vote choice. Ladd and Lenz performed several replications of Brader's models, with some extensions. In addition, they used panel data in their replications. Their findings support the AT and EA approach for influence of enthusiasm as a positive emotion, and strong evidence for the EA in case of anxiety. Therefore, they argue there is more evidence to support EA than AIT.

Marcus, MacKuen, and Neuman (2011) replied to Ladd and Lenz claiming that there are three important mistakes in the Ladd and Lenz replications. The first one is the choice of dependent variable. Ladd and Lenz replaced vote intention with feeling thermometers. The second one is assuming one-dimensionality of emotions, which they argue is a long-time proven wrong. The third mistake is the measurement error of anxiety, in combining feelings for both candidates into a single indicator. The authors argue that the right way is to use only one measure of feelings towards the candidate who is associated with the respondent's political affiliation. Marcus et al. (2011) performed several tests and ran various statistical models to show that even after extending additional survey waves and controlling for thermometer feelings the AIT still holds. In addition, the authors showed that the feeling thermometer and vote intention are distinct measures and should not be freely interchanged.

Renshon et al. (2015) contributed with another piece of puzzle to better understanding of emotions in political attitudes. The authors argue that the stimulus content is important, as the content related to politics might trigger causal paths other than emotions (e.g., ideology). Therefore, as Renshon et al. highlights, it is important to use non-political stimulus in experimental research. In their experiment, they showed that even the emotion that is incidental (unrelated) to political judgment can influence political attitudes. Another novelty Renshon et al. presented was in coupling the self-reported measurement of emotional state with psychophysiological measurement - skin-conductance reactivity. They found that the elevated skinconductance reactivity was successfully predicting the negative attitudes towards immigrants even after controlling for self-reported emotional state.

We argue that the findings of Renshon et al. (2015) open the discussion of the AIT explanatory power. The reason is that AIT claims that increased anxiety has only indirect influence on immigration attitudes in that it suppress the importance of heuristics and allows new information to be more influential (Marcus et al., 2011). Renshon et al. showed that increased anxiety led to more negative attitudes towards immigrants even if the experimental, anxiety-triggering video stimulus was incidental. However, Renshon et al. provided participants with stories on immigration as a part of the experimental design.

We do not claim that findings of Renshon et al. (2015) are against the AIT, rather we argue that the causal mechanism described by the AIT may not be necessarily the only one that links anxiety to immigration attitudes. The question whether anxiety may represent a direct link to change in immigration attitudes thus remains.

Although indirectly, Hatemi et al. (2013) also contributed to the discussion of emotion's role in immigration attitudes. The authors, focusing on the phobic-fear dispositions, brought a new element into studying the role of emotions and attitudes, which is a highlighted role of a stable, personality trait-based disposition, which is genetically informed. In other words, the authors focused on a stable, personal tendency to experience fear instead of the actual state of fear or anxiety. Hatemi et al. argue that the genetic influence lies in "regulating the level of anxiety and sensitivity to the out-group threat" (2013; p. 283). Their results show that fear and 
anxiety is related to immigrants and segregation attitudes, but not to liberal-conservative attitudes. The reason is that fear-induced anxiety works only with the political attitudes that involve in-group versus out-group relationships. Other empirical works also highlight the role of emotion in prejudicial attitudes, particularly when the attitudes regard in-group vs. outgroup division (Butz \& Yogeeswaran, 2011; Stephan et al., 2006; DeSteno et al., 2004; Voci \& Hewstone, 2003).

\section{The Aim of this Study}

In this study, we aim to investigate the relation between anxiety and selected political attitudes. Based on the researched above, we draw two hypotheses. The first hypothesis regards the relationship between anxiety feelings and political attitudes. We expect higher anxiety to lead to radicalized, more negative political attitudes, under the circumstances of experimentally imposed anxiety feelings by a stimulus that has no information value or content relation to the issue at hand. Second hypothesis places in a relationship the type of issue on the one hand, and the strength of anxiety's effect on the other hand. We expect the anxiety effect to be stronger in an issue involving the in-group/outgroup division (such as immigration) than in an issue with no such division (marijuana legalization).

Should the effect of anxiety be confirmed, this could mean that the political discourse based dominantly on negative emotions could lead to further polarization of society.

\section{Method}

\section{Participants}

We recruited 71 university students (47 females, 24 males) from the Faculty of Arts, Comenius University in Bratislava. The deci- sion to participate was completely voluntary, i.e. the participation was not enforced by teachers in any way. Students were offered 3 ECTS credits for participating in the experiment, and they were from various departments and study fields within the faculty. Participants were randomly assigned to three groups (17 females and 8 males in the experimental group, 16 females and 8 males in the relax condition group, $14 \mathrm{fe}-$ males and 8 males in the control group). As all the participants were regular, internal students at both bachelor (excluding the first year) and master level, we did not record their age. We estimate the age of participants to range from 19 to 23 .

\section{Procedure}

The experiments were conducted in small classrooms. Experimental procedure is depicted in Diagram 1.

After the subjects' arrival, we welcomed them and explained that they were going to complete three short, unrelated surveys and watch two short video clips in between the surveys. First, participants were applied sensors to measure psychophysiological reactivity. To measure heart rate two electrodes were attached to participants' bodies. Heart rate was measured by ECG monitoring system (described below) during the whole time the experiment was conducted.

Subsequently, participants were given further instructions. Following verbal instructions, participants filled out the pre-test questionnaire. Pre-test questionnaire contained items measuring the selected political attitudes under study, and several additional items so that the purpose of the experiment was not evident. Between the first (pre-test) and the second (personality traits) survey they watched a short video $(2 \mathrm{~min} 57 \mathrm{sec}$ ) full of relaxing images of lakes, trees or turtles slowly swimming in the sea, with calm music played as part of the video. 


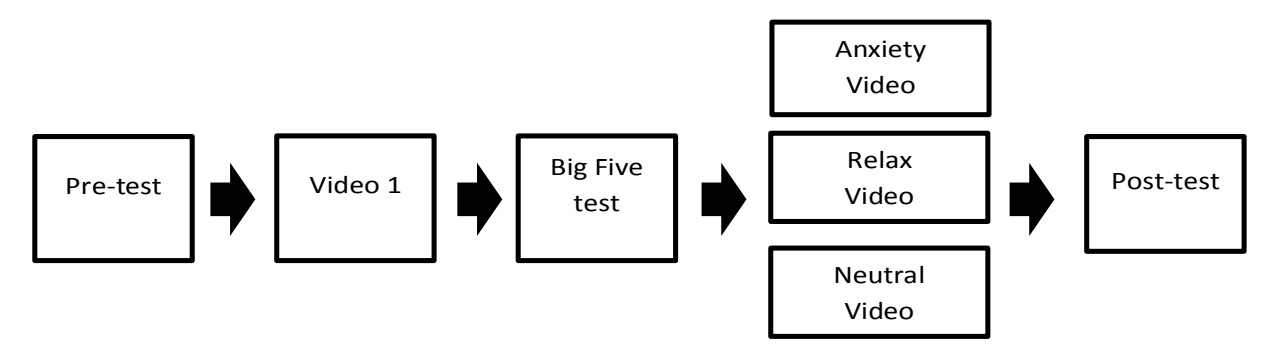

Diagram 1 Experimental design

The aim was to measure the bioelectrical activity of the heart at the baseline. After the relax video (same for all groups), participants filled out the second survey measuring personality traits, using the 60-item NEO Five-Factor Inventory(NEO-FFI; Costa \& McCrae, 1992; Slovak version Ruisel \& Halama, 2007). Between the second and the third survey, the participants watched the second, stimulus video.

The experimental group watched a short clip from the film Cliffhanger. We chose this film clip because it has been proved to trigger anxiety (Fredrickson \& Branigan, 2003; Renshon et al., 2015). By anxiety we mean undirected aversive arousal, which is distinguished from similar emotions (such as anger or fear) by lacking a clear object (Ohman, 2000; Renshon et al., 2015). The video clip is 2 min $32 \mathrm{sec}$ long and it shows a scene where a male mountain climber attempts to save a female climber, who is hanging above a rocky gorge, attached to a rope by a metal shackle that is slowly opening up and the female climber is about to fall. Although the woman character in the film eventually falls to her death, the clip shown to the experimental group ends before that time and the participants do not know the outcome.

The control group watched a neutral video with up to 20 various daily life objects with no sound (mostly simple pieces of furniture and means of transportation in black and white).
Third group watched a relaxing video with relaxing music played over visuals of abstract shapes and colors (4 min $15 \mathrm{sec}$ ). The purpose of this was to control the extent to which heart activity changes when going from the first relaxing video to neutral, compared to the relaxrelax condition.

After the manipulation video, we administered the post-test survey that included several sets of items. First, the post-test survey asked participants about the emotions they felt while watching the stimulus video. Second, we included items pertaining to the selected political attitudes under investigations. In addition to that, we included a set of items related to the video content, and other social issues. Again, the reason was to blur the main aim of the study.

\section{Measures}

\section{Anxiety Feeling}

We chose to measure physiological arousal as a change in heart rate activity. We admit that this measurement is, to a certain extent, less precise in sensitivity and speed of the subject's reaction to stimulus, when compared to skin conductance (EDA). However, both measures are equally well designed to capture the subject's activation. Measuring HR has another advantage; it is applicable in non-laboratory 
setting (Watson \& Gatchel, 1979; Li, Scott, \& Walters, 2015).

The heart rate was measured by the sensor eMotion Faros 90 (Mega Electronics Ltd., Finland), which is a non-invasive ECG monitoring system. The ECG frequency was set at $250 \mathrm{~Hz}$ and the HRV monitoring frequency at $1000 \mathrm{~Hz}$. Two electrodes were applied in the Lead II. position (negative pole under participant's right collar-bone and positive pole on participant's chest, left side in the area around the $13^{\text {th }} \mathrm{rib}$ ). We used the Kubios HRV 2.2 software to analyze the data.

We also measured self-reported feeling of anxiety as a part of post-test questionnaire. The question read: "Consider the short film clip you have just watched. To what extent did you feel the following emotions: anxiety?" The answers were recorded on a 7-point Likert scale, where the answer 0 read "I have not felt this emotion at all" and answer 6 read "I have felt this emotion very strongly".

\section{Neuroticism}

To measure neuroticism, we employed the Big Five personality test using the 60-item NEO Five-Factor Inventory (NEO-FFI; Costa \& McCrae, 1992, Slovak version Ruisel \& Halama, 2007). This measure has proved rather reliable (Gosling, Rentfrow, \& Swann, 2003) and takes relatively little time to administer. In our sample, the reliability of the subscale was tested as Cronbach's alpha resulting in $\alpha=0.762$.

\section{Political Attitudes}

In both the pre-test and post-test surveys we measured several attitudes towards various social issues so that participants could not easily find out the main point of interest of our research. The questionnaire included items on healthy lifestyle, environmental issues, healthcare issues. The item measuring attitudes to- wards immigrants asked to what degree participants agree with the following statement: "Slovakia should adopt such measures that would allow immigrants to get only the jobs that Slovak nationals do not want". This type of question is frequently used in public surveys to measure preferences towards immigration policies (Hainmueller, Hiscox, \& Margalit, 2015; Vašečka, 2009) and is regularly part of the World Value Survey. The item on marijuana legalization read: "Use of marijuana and other soft drugs should be legalized". Respondents were to state to what extent they agree with the statement on a 5-point Likert scale. Asking about attitudes towards marijuana legalization is not unusual in survey research (Eurobarometer 66, or surveys sponsored by the European Monitoring Centre for Drugs and Drug Addiction, carried out by national centers). In social, and particularly political science research, attitudes towards marijuana legalization are perceived as an indicator of social liberal thinking and are often used in relation to intelligence (Carl, 2014), literacy(Carl, Cofnas, \& Menie, 2016), and other concepts. The operationalization of dependent variable makes it clear that we focus on the preference rather than feelings, as part of attitudes (Zajonc, 1980; Hatemi et al., 2013).

\section{Data Analysis}

We use linear regression models to test the relationship between anxiety and neuroticism on the one hand and the change in policy attitudes on the other hand. Although 'difference in means' methods, such as ANOVA, have traditionally dominated in assessing experimental effects, several authors have recently advocated multivariate regression techniques to evaluate experimental results (Maxwell \& Delaney, 2004; Blair \& Imai, 2012). The main argument in favor of regression is that the statistical efficiency is much higher, resulting in considerably more precise estimates. Multivariate 
regression techniques, particularly in case of confounding control variables, are considered a standard technique (Morton \& Williams, 2010). Before running the regression analysis we checked that the necessary assumptions (linearity, normal distribution, absence of outliers, absence of multicollinearity and heteroscedasticity) were met.

We are aware of the rather small sample size, which is not a rare problem in experimental research. In order to ensure that model estimates are robust, we decided to use bootstrapping (Mooney \& Duval, 1993; Kline, 2011; Yung \& Bentler, 1996). In addition to robustness, "a greater degree of accuracy" is also an argument for bootstrapping with models of smaller sample size (Byrne, 2016, p. 369). For regression results without bootstrapping see Appendix.

\section{Results}

\section{Feeling of Anxiety}

First, we look at the possible effect the video manipulation had on our participants. Figure 1, the left-hand side shows the boxplots of selfreported anxiety feelings measured after the video stimulus. The figure indicates that while there is considerable difference in the level of self-reported anxiety feelings between the experimental group on the one hand, and the two other groups on the other hand, the change in ECG level is very similar in all three groups. Statistical tests confirm these findings. On the one hand, difference in self-reported anxiety between the experimental and control group is statistically significant $(t(45)=4.623, p<0.001)$, as well as between the experimental group and the relax group $(t(48)=7.681, p<0.001)$. Looking at the self-reported anxiety, the expected difference between the neutral and relax group is also significant $(t(45)=1.821, p=0.038)$. Tests of differences in ECG levels between the groups revealed no statistical difference in any of the combination (cliffhanger/neutral/relax).

\section{Effects of Anxiety on Attitudes towards Immigrants and Marijuana}

We test the effects of induced emotions by running several regression models. Table 1 shows the results. Model 1a (M1a) and 1b (M1b) focus on change in attitudes towards immigrants as the dependent variable. The difference between them is that for the assessment of the effect size of emotions, Model 1a uses

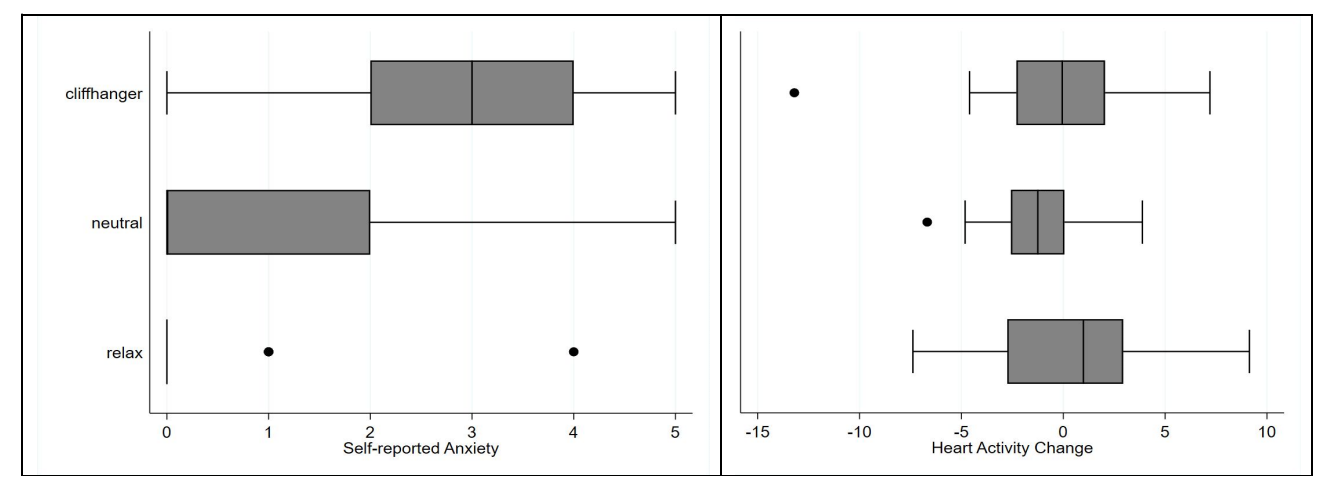

Figure 1 Change in anxiety between experimental and control group 
group assignment as a categorical variable, while Model $1 \mathrm{~b}$ uses self-reported anxiety measure. Models 2a (M2a) and 2b (M2b) focus on attitudes towards marijuana legalization as the dependent variable. Analogically, the difference between them is that Model $2 \mathrm{a}$ uses groups as a categorical variable, while Model $2 \mathrm{~b}$ uses selfreported anxiety measure.

Model 1a reveals that participants in the experimental group changed their position towards immigrants, on average, by 0.726 on a 5 -point scale. The change in attitudes was calculated in a way so that higher difference means higher degree of rejection, i.e. more radicalized attitude. Therefore, we can state that a switch from neutral to experimental group is associated with radicalized attitude towards immigrants. Model $1 \mathrm{~b}$ confirms this relationship by revealing that higher self-reported anxiety increases the change in attitudes by 0.139 . As we measured anxiety on a 7-point Likert scale, the maximum influence of anxiety (change from hypothetical minimum to hypothetical maximum) is thus 0.834 .
Considering that the attitudes towards immigrants are measured on a 5-point scale, we argue that the influence of induced anxiety is rather strong.

Models $2 \mathrm{a}$ and $2 \mathrm{~b}$ show that the experimental manipulation had no effect on the change of attitudes towards the legalization of marijuana, whether measured as experimental/control group membership or self-reported anxiety feelings. Despite no significant relationship in the "marijuana" models, this finding is substantial and relevant.

Findings regarding both dependent variables, attitudes towards immigrants and marijuana, are only partially in line with our expectations. Participants in the experimental group showed, on average, more radical attitudes towards immigrants than the control group (M1a). In addition, no difference was found between the control and relax group. Self-reported anxiety also led to radicalized attitudes (M1b). On the other hand, we found no effects of imposed anxiety feelings on attitude change towards marijuana

Table 1 Regression models (bootstrapped)

\begin{tabular}{lcccc}
\hline & $\begin{array}{c}\text { M1a: Change of } \\
\text { attitudes } \\
\text { towards } \\
\text { immigrants }\end{array}$ & $\begin{array}{c}\text { M1b: Change of } \\
\text { attitudes } \\
\text { towards } \\
\text { immigrants }\end{array}$ & $\begin{array}{c}\text { M2a: Change of } \\
\text { attitudes } \\
\text { towards } \\
\text { marijuana } \\
\text { legalization }\end{array}$ & $\begin{array}{c}\text { M2b: Change of } \\
\text { attitudes } \\
\text { towards } \\
\text { marijuana } \\
\text { legalization }\end{array}$ \\
\hline $\begin{array}{l}\text { Experimental group } \\
\text { b control group) }\end{array}$ & $0.726^{*}$ & & 0.047 & \\
$\begin{array}{l}\text { Relax group } \\
\text { Anxiety }\end{array}$ & 0.284 & & 0.066 & \\
Neuroticism & -0.020 & -0.022 & -0.000 & 0.115 \\
ECG change & -0.026 & -0.023 & 0.051 & -0.002 \\
constant & -0.214 & -0.017 & -0.046 & 0.046 \\
Wald statistic & $6.76(0.149)$ & $4.09(0.252)$ & $1.36(0.851)$ & $3.99(0.262)$ \\
df & 4 & 3 & 4 & 3 \\
$\mathrm{R}^{2}$ & 0.111 & 0.081 & 0.024 & 0.050 \\
$\mathbf{N}$ & 58 & 58 & 58 & 58 \\
\hline Note: ${ }^{2} \mathrm{p}<0.05$ & & & &
\end{tabular}


legalization. Based on the evidence we consider the first hypothesis only partially confirmed.

As expected in the second hypothesis, shifting from attitudes in the area with a clear ingroup versus out-group division to an area with no such clear division would decrease the effect of induced emotions. Our models show the effect size going down from relatively strong in the former case to non-existent in the latter case. Technically, we found the change of relationship in the expected direction, and thus we could argue the second hypothesis to be confirmed. However, we have to admit we did not expect the effect size in case of marijuana attitudes to diminish completely.

\section{Discussion}

\section{Effects of Anxiety on Radicalizing Political Attitudes}

Our results indicate that emotional arousal, particularly the feeling of anxiety, can influence anti-immigration attitudes in terms of radicalizing them. Such result is in accordance with previous research findings (Renshon et al., 2015). On the other hand, we found no evidence to support the hypothesized relationship between anxiety and marijuana attitudes.

On the one hand, the present study provides empirical evidence that emotional stimulus can have an effect on selected political attitudes formation, even if it is incidental to the decision-making process. As Bower (1981) has already pointed out, emotional arousal makes people recall experiences and information that are "affectively congruent". Thus, imposed anxiety as a negative emotion would cause people to recall similarly negative images or facts on immigrants. Consequently, this would translate into negative, anti-immigration attitudes. This is in line with previous research that linked variety of negative emotions (anger, disgust, fear and anxiety) to prejudicial atti- tudes towards outgroup members (Butz \& Yogeeswaran, 2011; Stephan et al., 2006; DeSteno et al., 2004; Voci \& Hewstone, 2003).

On the other hand, we admit that we investigated the effect of anxiety on attitudes change in just two, rather specific policy issues. Therefore, our findings should be taken as the first indication rather than confirmation of the negative effect of content-unrelated emotions on political attitudes. Further research including various policy attitudes is needed in this direction.

Additional to other research, we empirically demonstrated the direct effect, not only a mediated role of anxiety (e.g., Renshon et al., 2015). If future research also proves it to be true, imposing anxiety and anger by modern populists can have a long-lasting polarizing impact on societies. Realizing that the out-group/in-group division seems to be important, it is predominantly the relationship between the majoritarian part of society and various minorities that can suffer the most.

The fact that we did not find any evidence for an effect of anxiety on political attitudes towards legalization of marijuana may be explained by different nature of the problem. On the one hand, the immigration issues provide the potential for in-group/out-group identification. Moreover, the experiment was conducted about a month after the 2016 parliamentary election. The electoral campaign has intensely abused the issue of migration crisis that the whole EU suffered from. Strongly negative and intense public discourse could have imprinted a negative image of immigrants in society even after the election. Therefore, participants could have easily imagined a stereotyped, black, Muslim refugee despite the fact that the item in the questionnaire asked about labor migration from third countries. This could potentially bias the results as well. Future replication of this study could shed more light on the potential contextual bias of electoral campaign. 
On the other hand, marijuana legalization is an issue that is not based on identity divide but rather on social norms and values that dominate in society. This opens several avenues for the interpretation of our findings. First, in line with the hypothesized role of the out-group/ingroup divide, the role of anxiety may be weaker. Alternatively, experience with marijuana consumption could bias the results indirectly, although randomization should serve the purpose of controlling for unmeasured influences. However, if there were many participants with previous experience of marijuana use in all groups, the memory recollection at the time of reading the question may have brought associations that pre-determined the participants' attitudes and, thus, prevented the stimulus to exert influence. Lastly, there is also a statistical reason that potentially explains the insignificant effect of anxiety on attitudes towards marijuana decriminalization. The reason is that our study is working with relatively small sample size (72 participants), although not unusually small in this type of research (a sample size below 100 participants is most often used in psychological studies, as shown by Kühberger, Fritz, \& Scherndl, 2014). Increasing the sample size should strengthen the statistical significance of the results, although it should not automatically change the size of anxiety effects on political attitudes.

As there is a fair amount of literature highlighting the role of genetic predisposition in anxiety feelings (see review i.e., in Clément, Calatayud, \& Belzung, 2002), we included a personality feature of neuroticism as a control variable in our models. Despite having no hypothesis regarding neuroticism directly, we will touch upon it at least minimally here. The effects of neuroticism were not statistically significant, thus indicating no role for this personality trait in affecting political attitudes. On the other hand, it is important to note that the actual level of anxiety feelings was part of the regression model. Although the
Variance Inflation Factor (VIF) indicated no multicollinearity problem, lack of statistical significance for a measure of tendency to anxiety feelings maybepartially explained by capturing the actual state of anxiety feelings.

\section{Study Limitations}

Our study was not without limitations. While the self-reported anxiety among participants proved to rise after being exposed to the stimulus, the measures of ECG levels between the groups revealed no statistically relevant differences among the groups. Thus, we have to admit: subjectively reported emotions were not objectively supported by physiological arousal measured by ECG. One possible explanation for such discrepancy might point to the environmental set up of the experiment. Experimental treatment carried out in a classroom, as opposed to individually performed tests in a laboratory setting might influence the intensity of the experience of the imposed anxiety (Frijda, 1988), which can subsequently impact the psychophysiological emotional demonstrations causing insignificance of ECG change between groups. In addition, there may have been several other minor distractions during the experiment that may have caused the heart activity to increase without the researchers' intentions (i.e., possible group effect, minor audio disturbances in the environment, gender of the administrators...). If this had happened, particularly in the relax or control group, it would have led to insignificant differences in the measurements.

Second, our research design does not bring us certainty in terms of the extent to which the findings based on immigration attitudes can be generalized to other issues, even if limited to areas including in-group/out-group divide. On the one hand, it seems natural that the effect of anxiety on change of attitudes towards immigrants should be, to a certain degree, transferable to issues related to other minorities, in- 
cluding not only ethnic, but also sexual and religious minorities. However, due to the unprecedented migration wave of 2015 and the way it was abused in the public discourse in Slovakia (a rather radicalized discourse itself), it is possible that the attitudes towards immigration cannot be representative of other types of political attitudes and should be kept in a strictly separate category. Future research will have to decide on this.

Finally, our research design has a limitation in regard to time dimension of the attitude change caused by imposed anxiety. As our posttest questionnaire was administered shortly after the stimulus, our models can only estimate a short-time change in attitudes. On the one hand, it is possible that without any further emotional manipulation the attitudes towards immigration become less negative again, and reach the original level. However, in reality there is perpetual abuse of negative emotions in populist politics, which can have long-term impact on further radicalization of political attitudes.

\section{References}

Baboš, P., Világi, A., \& Oravcová, V. (2016). Spoločenské problémy, politické (ne)riěsenia: Volby 2016. [Social problems, political (non-)solutions: The 2016 elections.] Bratislava, Slovakia: STIMUL.

Babiš, A. (2013): Deník nepolitika: Lány a bazén už mi zabrali... [The diary of a non-politician: Lány and the pool has been already taken... ]. Blog, available online on 20 July 2018 at https://andrejbabis. blog.idnes.cz/blog.aspx?c=374378

Blair, G., \& Imai, K. (2012). Statistical analysis of list experiments. Political Analysis, 20(1), 47-77. https://doi.org/10.1093/pan/mpr048

Bower, G. H. (1981). Mood and memory. American Psychologist, 36(2), 129-148. http://dx.doi.org/ 10.1037/0003-066X.36.2.129

Brader, T. (2005). Striking a responsive chord: How political ads motivate and persuade voters by appealing to emotions. American Journal of Political Science, 49(2), 388-405. https://doi.org/10.1111/ j.0092-5853.2005.00130.x

Brader, T., Valentino, N. A., \& Suhay, E. (2008). What triggers public opposition to immigration? Anxiety, group cues, and immigration threat. American Jour- nal of Political Science, 52(4), 959-978. https:// doi.org/10.1111/j.1540-5907.2008.00353.x

Byrne, B. M. (2016). Structural equation modeling with AMOS: Basic concepts, applications, and programming. London: Routledge.

Butz, D., \& Yogeeswaran, K. (2011). A new threat in the air: Macroeconomic threat increases prejudice against Asian Americans. Journal of Experimental Social Psychology, 47(1), 22-27. https://doi.org/ 10.1016/j.jesp.2010.07.014

Costa Jr., P. T., \& McCrae, R. R. (1992). Revised NEO Personality Inventory (NEO-PI-R) and NEO FiveFactor Inventory (NEO-FFI) professional manual. Odessa, FL: Psychological Assessment Resources.

Carl, N. (2014). Verbal intelligence is correlated with socially and economically liberal beliefs. Intelligence, 44, 142-148. https://doi.org/10.1016/j.intell.2014. 03.005

Carl, N., Cofnas, N., \& of Menie, M. A. W. (2016). Scientific literacy, optimism about science and conservatism. Personality and Individual Differences, 94, 299-302. https://doi.org/10.1016/j.paid.2016. 01.046

Clément, Y., Calatayud, F., \& Belzung, C. (2002). Genetic basis of anxiety-like behaviour: A critical review. Brain Research Bulletin, 57(1), 57-71. http: //dx.doi.org/10.1016/S0361-9230(01)00637-2

DeSteno, D., Dasgupta, N., Bartlett, M., \& Cajdric, A (2004). Prejudice from thin air. Psychological Science, 15(5), 319-324. https://doi.org/10.1111/ j.0956-7976.2004.00676.x

Eagly, A., \& Chaiken, S. (1993). The psychology of attitudes. Fort Worth, TX: Harcourt.

Fredrickson, B., \& Branigan, C. (2003). Positive emotions broaden the scope of attention and thought-action repertoires. Cognition \& Emotion, 19(3), 313-332. https://doi.org/10.1080/ 02699930441000238

Frijda, N. H. (1988). The laws of emotion. American Psychologist, 43(5), 349-358. http://dx.doi.org/ 10.1037/0003-066X.43.5.349

Gilens, M. (1999). Why Americans hate welfare. Chicago: University of Chicago Press.

Gosling, S. D., Rentfrow, P. J., \& Swann Jr., W. B. (2003). A very brief measure of the Big-Five personality domains. Journal of Research in Personality, 37(6), 504-528. https://doi.org/10.1016/S00926566(03)00046-1

Hainmueller, J., \& Hopkins, D. J. (2014). Public attitudes toward immigration. Annual Review of Political Science, 17, 225-49. https://doi.org/10.1146/ annurev-polisci-102512-194818

Hainmueller, J., Hiscox, M. J., \& Margalit, Y. (2015). Do concerns about labor market competition shape attitudes toward immigration? New evidence. Jour- 
nal of International Economics, 97(1), 193-207. https://doi.org/10.1016/j.jinteco.2014.12.010

Haerpfer, Ch., Wallace, C. (1998). Xenophobic attitudes towards migrants and ethnic minorities in Central and Eastern Europe. In F. H. Columbus (Ed.), Central and Eastern Europe in Transition (Vol. I, pp. 183-213). NY: Nova Science Publishers, Inc.

Hatemi, P. K., McDermott, R., Eaves, L. J., Kendler, K. S., \& Neale, M. C. (2013). Fear as a disposition and an emotional state: A genetic and environmental approach to out-group political preferences. American Journal of Political Science, 57(2), 279293. https://doi.org/10.1111/ajps.12016

Huddy, L., Feldman, S., Taber, C., \& Lahav, G. (2005). Threat, anxiety, and support of antiterrorism policies. American Journal of Political Science, 49(3), 593-608. https://doi.org/10.1111/j.1540-5907. 2005.00144.x

Jerit, J. (2004). Survival of the fittest: Rhetoric during the course of an election campaign. Political Psychology, 25(4), 563-575. https://doi.org/10.1111/ j.1467-9221.2004.00387.x

Kline, R. B. (2011). Principles and practice of structural equation modeling. New York: The Guilford Press.

Kühberger, A., Fritz, A., \& Scherndl, T. (2014). Publication bias in psychology: A diagnosis based on the correlation between effect size and sample size. PloS one, 9(9). https://doi.org/10.1371/journal.pone. 0105825 .

Ladd, J. M., \& Lenz, G. S. (2008). Reassessing the role of anxiety in vote choice. Political Psychology, 29(2), 275-296. https://doi.org/10.1111/j.14679221.2008.00626.x

Li, S., Scott, N., \& Walters, G. (2015). Current and potential methods for measuring emotion in tourism experiences: A review. Current Issues in Tourism, 18(9), 805-827. https://doi.org/10.1080/ 13683500.2014 .975679

Marcus, G. E., Neuman, W. R., \& MacKuen, M. (2000). Affective intelligence and political judgment. Chicago: University of Chicago Press.

Marcus, G., MacKuen, M., \& Neuman, W. R. (2011). Parsimony and complexity: Developing and testing theories of affective intelligence. Political Psychology, 32(2), 323-336. https://doi.org/10.1111/j.1467$9221.2010 .00806 . x$

Maxwell, S. E., \& Delaney, H. D. (2004). Designing experiments and analyzing data 2. New Jersey: Lawrence Erlbaum.

Mendelberg, T. (2001). The race card. Princeton, NJ: Princeton University Press.

Mooney, C. Z., \& Duval, R. D. (1993). Bootstrapping. A nonparametric approach to statistical inference. Sage University Paper series on Quantitative Appli- cations in the Social Sciences, series no. 07-095. Newbury Park, CA: Sage.

Mudde, C., \& Kaltwasser, C. R. (2012). Populism and (liberal) democracy: A framework for analysis. In C. Mudde \& C. R. Kaltwasser (Eds.). Populism in Europe and Americas: Threat or correctives for democracy? (pp. 1-27), Cambridge: CUP.

Nelson, T. E., \& Kinder, D. E. (1996). Issue frames and group-centrism in American public opinion. Journal of Politics, 58(4), 1055-1078. https://doi.org/ $10.2307 / 2960149$

Öhman, A. (2000). Fear and anxiety: Evolutionary, cognitive, and clinical perspectives. In M. Lewis \& J. M. Haviland-Jones (Eds.), Handbook of emotions (pp. 573-593). New York, NY: Guilford Press.

Renshon, J., Lee, J. J., \& Tingley, D. (2015). Physiological arousal and political beliefs. Political Psychology, 36(5), 569-585. https://doi.org/10.1111/ pops. 12173

Ruisel, I., \& Halama, P. (2007). NEO-FFI. NEO pätfaktorový osobnostný inventár. [NEO Five Factor Inventory]. Praha: Hofrege, Testcentrum.

Small, D. A., \& Lerner, J. S. (2008). Emotional policy: Personal sadness and anger shape judgments about a welfare case. Political Psychology, 29(2), 149-168. https://doi.org/10.1111/j.1467-9221.2008.00621.x

Stephan, W. G., Ybarra, O., \& Bachman, G. (2006). Prejudice toward immigrants. Journal of Applied Social Psychology, 29(11), 2221-2237. https:// doi.org/10.1108/JACPR-03-2016-0217

Valentino, N. A., Hutchings, V. L., \& White, I. (2002). Cues that matter: How political ads prime racial attitudes during campaigns. American Political Science Review, 96(1), 75-90. https://doi.org/10.1017/ S0003055402004240

Vašečka, M. (2009). Postoje verejnosti $k$ cudzincom a zahraničnej migrácii v Slovenskej republike [Public attitudes towards foreigners and foreign migration in the Slovak Republic]. Bratislava: International Office for Migration.

Voci, A., \& Hewstone, M. (2003). Intergroup contact and prejudice toward immigrants in Italy: The mediational role of anxiety and the moderational role of group salience. Group Processes \& Intergroup Relations, 6(1), 37-54. https://doi.org/10.1177/ 1368430203006001011

Watson, P. J., \& Gatchel, R. J. (1979). Autonomic measures of advertising. Journal of Advertising Research, 19(3), 15-26.

Yung, Y-F., \& Bentler, P. M. (1996). Bootstrapping techniques in analysis of mean and covariance structures. In G. A. Marcoulides \& R. E. Schumacker (Eds.). Advanced structural equation modeling: Issues and techniques (pp. 195-226). Mahwah, NJ: Erlbaum. 
Zajonc, R. B. (1980). Feeling and thinking: Preferences need no inferences. American Psychologist,
35(2), 151-175. http://dx.doi.org/10.1037/0003 066X.35.2.151

\section{Appendix}

Regression results without bootstrapping

\begin{tabular}{|c|c|c|c|c|}
\hline & $\begin{array}{l}\text { M1a: Change of } \\
\text { attitudes } \\
\text { towards } \\
\text { immigrants }\end{array}$ & $\begin{array}{c}\text { M1b: Change of } \\
\text { attitudes } \\
\text { towards } \\
\text { immigrants }\end{array}$ & $\begin{array}{l}\text { M2a: Change of } \\
\text { attitudes } \\
\text { towards } \\
\text { marijuana } \\
\text { legalization }\end{array}$ & $\begin{array}{c}\text { M2b: Change of } \\
\text { attitudes } \\
\text { towards } \\
\text { marijuana } \\
\text { legalization }\end{array}$ \\
\hline $\begin{array}{l}\text { Experimental group } \\
(\mathrm{b}=\text { control group) }\end{array}$ & $0.726^{*}$ & & 0.047 & \\
\hline Relax group & 0.284 & & 0.066 & \\
\hline Anxiety & & $0.139^{(a)}$ & & 0.115 \\
\hline Neuroticism & -0.020 & -0.022 & -0.000 & -0.002 \\
\hline ECG change & -0.026 & -0.023 & 0.051 & 0.046 \\
\hline constant & -0.214 & -0.017 & -0.046 & -0.123 \\
\hline F (p-value) & $1.66(0.174)$ & $1.59(0.201)$ & $0.32(0.860)$ & $0.95(0.422)$ \\
\hline df & 4 & 3 & 4 & 3 \\
\hline $\mathrm{R}^{2}$ & 0.111 & 0.081 & 0.024 & 0.050 \\
\hline $\mathbf{N}$ & 58 & 58 & 58 & 58 \\
\hline
\end{tabular}

(a) - coefficient is significant at 0.01 level 